\title{
Effects of Reference Form on Frequency of Mention and Rate of Pronominalization
}

\author{
Sofiana Iulia Chiriacescu ${ }^{1}$ \\ ${ }^{1}$ Institute of Linguistics, University of Stuttgart \\ Keplerstr. 17, 70174 Stuttgart, Germany \\ \{Sofiana.Chiriacescu\}@ling.uni-stuttgart.de
}

\begin{abstract}
Comprehension studies find that a referent, which is expected to be picked up more often in the subsequent discourse, is also more prone to be realized by means of a more reduced type of referring expression (typically a pronoun), compared to a referent that is less expected to be re-mentioned (Ariel 1988, Arnold 1998). This paper evaluates this assumption and shows that it does not always hold. Specifically, I take a closer look at the effects of choice of indefinite referential form in English and German on likelihood of subsequent mention and likelihood of subsequent pronominalization. The results of two experimental studies suggest that these two factors, which pertain to the upcoming discourse, should be separated, as they point into different directions. While the type of referring expression used to introduce a referent impacts its frequency of subsequent mention, the rate of pronominalization seems to be dependent on other characteristics of the referent.
\end{abstract}

Keywords: German, English, reference, pronominalization, topic, psycholinguistics.

Pre-print version. To appear in: I. Hendrickx, S. Lalitha Devi, A. Branco \&R. Mitkov (eds.). Anaphora and Reference Resolution. Selected papers of the 8th Discourse Anaphora and Anaphor Resolution Colloquium. Heidelberg: Springer. 


\section{Introduction}

One of the fundamental questions underlying theories of language production and comprehension concerns referent tracking, including what referents are preferred to be picked up in the subsequent discourse and what type of referring expressions are used for this purpose. Psycholinguistic studies concerned with some of these aspects showed that different factors play a role in determining the referent that will be more readily and more often talked about in the subsequent discourse (Givón 1983, Arnold 1998, Chiriacescu 2011). Syntactic or semantic prominence, parallel constructions or particular coherence relations can be enumerated as examples of such factors that impact the likelihood of subsequent mention. The high expectancy of subsequent mention of a referent correlates with its stronger tendency of that referent to be realized by means of a more reduced type of referring expression (typically a pronoun). The association between likelihood of subsequent mention and rate of pronominalization have been considered epiphenomena of a referent's high accessibility or activation level (Arnold 1998, Ariel 1988).

This paper presents and discusses two studies that investigate the effects of choice of indefinite referential form in English and German on likelihood of subsequent mention and likelihood of subsequent pronominalization. The two constructions that are of special interest for the present investigation are given in (1) for English, and (2) for German, respectively.

He put on this 31 cent stamp on the envelope, and realized only later that it was worth a fortune because it was unperforated.

(Maclaran 1982: 88)

In unserer Stadt gibt's so'nen Mann, er ist nicht irgendeiner, nein, er ist unser neuer Bürgermeister, er sieht wie ein Vogelstrauß, $[\ldots]^{1}$.

'In our city there is so-a man, he is not anyone, no, he is our new mayor, he looks like an ostrich [...].'

The general picture about English is that it developed the indefinite determiner this for referents that are (going to be) more accessible, activated or topical in the subsequent discourse (Prince 1981, Maclaran 1982). This is mirrored by the high referential continuity of such referents. German has not only one, but two indefinite demonstratives that correspond to English this, namely the indefinite dieser and so'n (von Heusinger 2010). In this paper I focus on indefinite so' $n$, which is formed from the demonstrative for properties so and the reduced form of the simple indefinite article ' $n$. I test whether German $s o$ ' $n$, as in (2), has similar discourse effects to English indefinite this. If the assumption about the higher accessibility of these referents is true, and in light of previous findings (see Gernsbacher \& Shroyer 1989, among others), then passages should more often continue talking about referents preceded by this or $s o$ 'n as compared to a simple indefinite noun phrase, and perhaps such re-mentions should be pronominalized more often as well.

${ }^{1}$ http://www.mzee.com/forum/archive/index.php/t-100000620.html 
The results of the sentence-completion studies presented in this paper only partially confirm this assumption. Participants prefer to continue talking about referents, whenever these referents are preceded by English this or German so'n. However, the prediction about a higher rate of pronominalization for the marked referents is not met, as referents headed by this and $s o$ 'n tend to be picked up by lexically more elaborated types of noun phrases. This latter finding underlines the necessity to dissociate between likelihood of pronominalization and referential persistence (confirmation of more recent studies conducted by Kehler et al. 2008, Chiriacescu \& von Heusinger 2010, Kaiser 2010). Overall, the findings of this paper cast new light on the notions of accessibility, activation or prominence operationalized in terms of referential persistence and likelihood of pronominalization as equally weighted factors.

The structure of this paper is as follows. In Section 2 I sketch out the main observations made with respect to the discourse behaviour of indefinite noun phrases headed by this in English and so'n in German. Section 3 presents and discusses two sentence-completion experiments that investigate the discourse effects of indefinite noun phrases preceded by indefinite this in English and $s o$ ' $n$ in German. The findings made in this paper and directions for further research are discussed in the last section.

\section{English indefinite this and German so'n}

Depending on the context of use, the English determiner this can be either definite or indefinite (Prince 1981, Maclaran 1982, among others). This paper focuses on the latter use of this, which occurs in colloquial, mainly conversational English. In (3), only the first two instances of this (i.e. this guy, this story) are indefinite, whereas the third this in Look at this book is an instantiation of the stressed, deictic, definite use of this.

(3) Well, I met this guy last night that is a year older than me at a pool party in San Francisco (Well I live in LA but I was visiting family) and he told me this story about dolphins. Look at this book he gave me $[\ldots]^{2} \quad$ (emphasis mine)

An analysis of English indefinite this is interesting for several reasons. First, as opposed to the proximal demonstrative this, indefinite this does not bear main stress and serves to introduce hearer-new and discourse-new referents in the discourse. Second, indefinite noun phrases headed by this tend to have referential meanings (i.e. take wide scope with respect to different operators, are epistemically specific, etc.). And third, besides being semantically specific, indefinites headed by this serve as a signal to the hearer that more information about the referent in question will follow (Prince 1981, Wright \& Givón 1987, Gernsbacher \& Shroyer 1989), thus, being (discourse-) pragmatically specific as well ${ }^{3}$.

2 http://www.ihav.net/vb/introductions/i-met-him-last-night-358268.html[viewed: March 2009]

3 This paper deals only with the discourse effects of this-referents, but see Chiriacescu (2010, 2011) and von Heusinger (2011) for a more ample presentation of the characteristics of so'n. 
The discourse effects of indefinite this as opposed to those of the simple indefinite article $a(n)$ have been tested in few studies. Wright \& Givón (1987), for example, extended an experimental investigation initially conducted by Prince (1981). They recorded eight- and nine-year-old children telling one another stories and found out that children chose to use this for referents that they would continue talking about and $a(n)$ for referents that they would rather not pick up in the following discourse. More exactly, the average was 5.32 times for concepts introduced by this and 0.68 times when concepts were introduced by $a(n)$.

In a more ample investigation, Gernsbacher \& Shroyer (1989) explained the use of this over $a(n)$ in terms of different degrees of accessibility of a referent on the hearer's side. They assume that accessible referents are: (i) mentioned more often in the subsequent discourse (this metric corresponds to Givón's (1983) textual method referential persistence), are (ii) mentioned earlier in the subsequent discourse, and are (iii) taken up with more attenuated types of referring expressions (i.e. pronouns) in the subsequent discourse. Less accessible referents are predicted to show low values for all three factors. In an auditory sentence-continuation task participants were asked to continue narratives within 30 seconds after hearing the last sentence of each target narrative. The last sentence of each target consisted of a noun phrase which was either headed by indefinite this or by the simple indefinite article $a(n)$. Their findings confirm their predictions, as referents headed by this, as opposed to referents headed by the simple indefinite article are mentioned more often (i.e. 4.05 times for thisindefinites vs. 2.76 times for $a$-indefinites) in the immediately following sentence after being introduced in the discourse. Moreover, indefinites headed by this, as opposed to the $a$-indefinites, were show to need less lexical material (e.g. zero anaphors and pronouns) to be picked up for the first time in the subsequent discourse. Based on these results, Gernsbacher \& Shroyer (1989) consider that entities introduced by indefinite this, as opposed to $a(n)$, are "more accessible (i.e. more focussed, foregrounded or topical) from listeners' mental representations" and therefore more easily retrievable from memory.

More recent studies showed that other languages developed similar means to introduce referents that play a preferential role in the subsequent discourse (Haspelmath 1997, Lyons 1999). The use of the German determiner so'n in 'out-ofthe-blue' contexts (i.e. in contexts in which the noun phrase preceded by so' $n$ lacks an antecedent or an accompanying pointing gesture) comes close to that of English indefinite this. First, similar to English indefinite this, indefinite noun phrases headed by $s o$ ' $n$ are used to introduce new referents in the discourse and show a preference for referential readings. Second, so'n indefinites are more prone to be picked up in the following discourse compared to noun phrases headed by the simple indefinite article (Chiriacescu 2010, 2011, von Heusinger 2011).

In the following section I test the discourse effects of indefinite noun phrases headed by $s o$ ' $n$ in German and compare the results of this study with a parallel experiment, which tested the impact of English indefinite this on the subsequent discourse along the same lines. The current investigations differ from previous experimental studies (e.g. Prince's 1981, or Gernsbacher \& Shroyer 1989), as the referents headed by the two indefinite markers are characterized by the semantic feature [+human] (vs. Gernsbacher \& Shroyer 1989) and appear in direct object position. I coded for two factors: (i) whether referents introduced by means of 
indefinite so'n in German are more frequently re-mentioned in the subsequent discourse compared to their simple indefinite counterparts, and (ii) whether the preferred type of anaphoric expression used to pick up these referents for the first time in a matrix clause is less elaborate than the type of anaphoric expression used to re-mention the referents associated with simple indefinite noun phrases. In light of previous findings on the accessibility of referents in general and on the discourse effects of English indefinite this in particular, the prediction with respect to the two factors can be formulated as follows:

(4) Prediction 1 (referential persistence)

Referents headed by indefinite this in English and $s o$ ' $n$ in German will show a higher frequency of subsequent re-mention compared to their simple indefinite counterparts.

(5) Prediction 2 (first anaphoric expression)

Referents headed by indefinite this in English and $s o$ ' $n$ in German will show a higher likelihood of pronominalization compared to their simple indefinite counterparts.

\section{The Sentence-Completion Experiments}

To evaluate the discourse effects of indefinite noun phrases preceded by indefinite this in English and so'n in German, two similar experiments were constructed. I will refer to the experiment testing the English data as Exp1 and to the experiment testing the German data as Exp2. I coded for two parameters of the referents in question, namely: (i) referential persistence (i.e. the frequency of mention of a referent in the subsequent discourse) and (ii) the type of co-referential expression used to refer back for the first time to the referent introduced by the target referent ${ }^{4}$. The referents associated with both types of indefinite noun phrases are predicted to be more referentially continuous in the subsequent discourse and to require less lexical material when being picked up for the first time in the subsequent discourse. Furthermore, if the presence of German so'n has comparable discourse effects to those of the English indefinite determiner this, then the results of the two experiments are expected to be similar.

\footnotetext{
${ }^{4}$ Independently of these two factors, in Chiriacescu (2011) I also investigated the topic shift potential of referents headed by this in English and so'n in German (i.e. the potential of referents mentioned in non-subject positions to become subjects in a subsequent matrix clause). I will not discuss the findings of this metric in this paper, but note that under controlled situations, referents realized as direct objects and which were preceded by indefinite this and $s o$ 'n make better candidates to shift the topic of the current discourse (i.e. to become subjects), compared to similar referents preceded by the simple indefinite article.
} 


\subsection{Method, Procedure and Data Analysis}

The methodology used was an open-ended sentence continuation task with three test items (see Gernsbacher \& Shroyer 1989, or Chiriacescu \& von Heusinger 2010 for a detailed description of similar tasks). As both English this and German so'n are more frequently used in direct object position, all target referents were constructed in this syntactic position. Moreover, the given mini-discourses were kept in a colloquial tone, because both English indefinite this and German so'n occur in conversational language.

Participants ( $n=20$ for Exp1 and $n=20$ for Exp2) read 3 mini-discourses and were instructed to add 5 logical and natural-sounding sentence continuations to each of them. I manipulated the morphological realization of the target referents, which resulted in two conditions for each experiment, i.e. one in which the direct object realized as an indefinite unmodified noun phrase is headed by this, in Exp1, and by so'n in Exp2, (see the left columns of Tables 1 and 2), and one in which the same direct object is headed by the simple indefinite article $a(n)$ in English and ein (e) in German (see the right columns of Tables 1 and 2). This was a between-subjects manipulation, which means that a participant either completed a version of the study where all three targets contained simple indefinites, or a version where all three targets contained this-indefinites in Exp1 or so'n-indefinites in Exp2, respectively.

Table 1. Sample experimental item from Experiment 1 on English

\begin{tabular}{|c|c|}
\hline this-condition & $a(n)$-condition \\
\hline $\begin{array}{l}\text { Yesterday evening was so warm that } \\
\text { James }_{1} \text { decided to hang out with friends } \\
\text { at the local coffee shop. On his }{ }_{1} \text { way } \\
\text { downtown, he }{ }_{1} \text { saw this kid } \text { coming }_{2} \\
\text { down the street. }\end{array}$ & $\begin{array}{l}\text { Yesterday evening was so warm that } \\
\text { James }_{1} \text { decided to hang out with friends } \\
\text { at the local coffee shop. On his }{ }_{1} \text { way } \\
\text { downtown, he }{ }_{1} \text { saw a kid } \text { coming down }_{2} \text { coming } \\
\text { the street. }\end{array}$ \\
\hline
\end{tabular}

Table 2. Sample experimental item from Experiment 2 on German

\begin{tabular}{|c|c|}
\hline so'n-condition & ein $(e)$-condition \\
\hline Draußen war es warm. Peter ${ }_{1}$ hielt es zu & Draußen war es warm. Peter ${ }_{1}$ hielt es zu \\
\hline Hause einfach nicht mehr aus und ging & Hause einfach nicht mehr aus und ging \\
\hline in die Stadt. Auf dem Weg dorthin sah & in die Stadt. Auf dem Weg dorthin sah \\
\hline $\begin{array}{l}\text { er }_{1} \text { so'nen Jungen } \\
\text { betreten. }\end{array}$ & Jungen $_{2}$ einen Laden betreten. \\
\hline 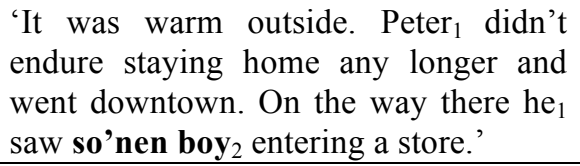 & $\begin{array}{l}\text { 'It was warm outside. Peter }{ }_{1} \text { didn't } \\
\text { endure staying home any longer and } \\
\text { went downtown. On the way there he } \\
\text { saw a boy }{ }_{2} \text { entering a store.' }\end{array}$ \\
\hline
\end{tabular}

The fact that each test item consisted of two or three sentences made it difficult to control and eventually code every aspect of the mini-discourses, but it provided the greater advantage of creating a natural discourse and of combining comprehension and production processes. For each continuation story provided by a participant, I 
coded the first five main clauses (and any associated subordinate clause). The grammatical subject of the first and second sentence (e.g. Peter in the test item in Table 2) received subscript 1 . Subscript 2 was used for the indefinite noun phrase whose form was manipulated in the critical sentence (e.g. so'nen Jungen ('so'nen boy') in Table 2).

The referential persistence of each referent introduced in the mini-discourse was explored. Each occurrence of the same referent in every continuation sentence was added up to a sum representing the referential persistence of that referent (i.e. cumulative value). Comparing the values for referential persistence of all referents, we gain insights into the exact stage in the discourse at which the critical referent has a greater cumulative persistence value than the initial subject referent.

The second aspect coded was the type of referring expression used to pick up the target referent for the first time in the upcoming discourse. For each continuation, I investigated whether participants used a zero anaphor, a pronoun, a definite unmodified noun phrase, or a definite modified noun phrase as the first co-referential expression in a matrix clause. I did not consider following anaphoric expressions referring to the same target referent after its first mention in the subsequent discourse.

\subsection{Results}

Participants provided 20 responses for each of the two experiments (Exp1 and Exp2). Overall, the results underline the preferential discourse status of indefinite noun phrases headed by English this and German so'n compared to that of indefinite noun phrases headed by the simple indefinite article. In the following, I discuss the findings from both experiments in more detail.

Referential persistence. Several observations can be made with respect to the findings of the referential persistence of referents in Exp1 and Exp2. Figure 1 summarizes the mean values for referential persistence of the referents of test items 13 (TI1-TI3) in Exp1 on English. Prediction 1 in (4) was confirmed for the English data, as referents associated with this-indefinites were more frequently picked up in the subsequent discourse compared to the referents of the $a(n)$-indefinites.

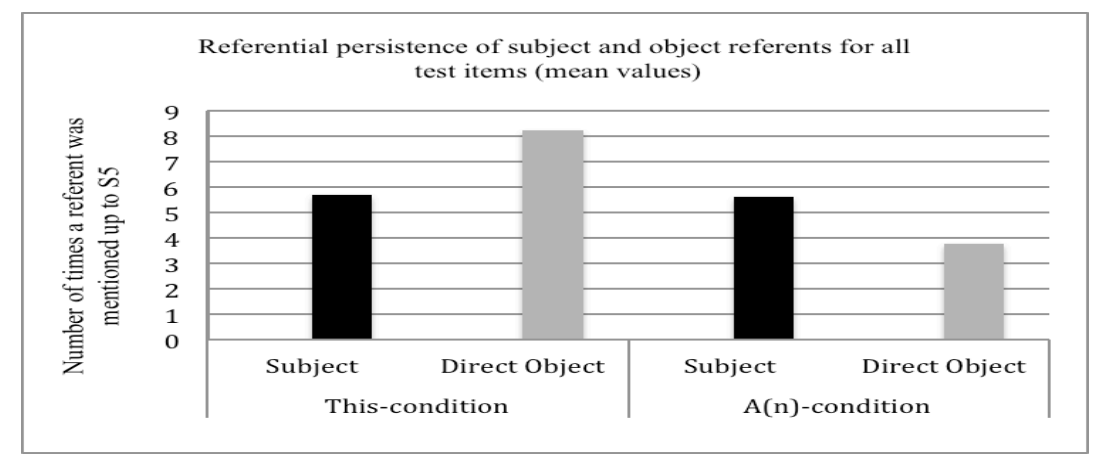

Fig. 1. Referential persistence of all referents introduced in the initial mini-discourses in all test items up to S5 (average per continuation stories) in Experiment 1. 
Similar to the findings of Exp1, the referents associated with indefinite noun phrases preceded by German so'n behave differently with respect to their referential persistence compared to simple indefinite noun phrases. Specifically, for the so' $n$ condition, we notice a high likelihood for the direct object referents to be picked up frequently in the following discourse. In contrast, in the ein(e)-condition, direct object referents are mentioned less often in the subsequent discourse. The results reported so far confirm the Prediction 1 in (4), as the marked referents display a higher rate of subsequent mention compared to the referents preceded by the simple indefinite article.

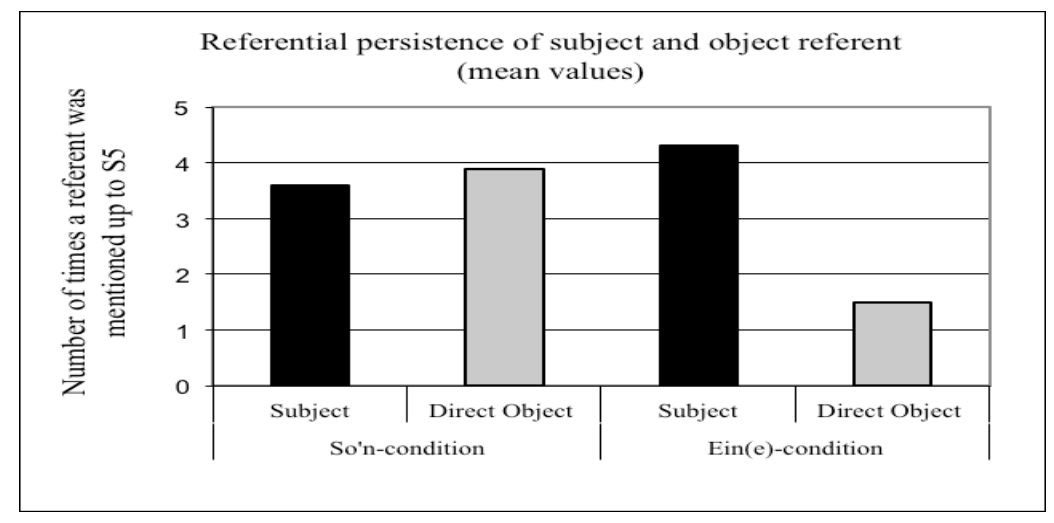

Fig. 2. Referential persistence of all referents introduced in the initial mini-discourses in all test items up to S5 (average per continuation stories) in Experiment 2.

The first anaphoric expression. The second factor investigated was the type of referring expression used to refer back to the target items for the first time in the continuation sentences provided by the participants. Tables 3 and 4 display the absolute and mean values of this characteristic for the target referents in Exp1 (this vs. $a(n)$ referents) and Tables 5 and 6 display the same values for the target referents in Exp2 (so'n vs. ein(e)). Recall that ten different participants provided continuations for each of the three target items per condition, resulting in 30 continuations for the thiscondition, another 30 for the $a(n)$-condition, 30 continuations for the $s o$ 'n-condition and 30 continuations for the ein(e)-condition. The tables show that for the thiscondition, two participants (i.e. $7.7 \%$ in Table 3) chose not to mention the direct object referent again in a matrix clause, whereas for the $s o$ 'n condition, only one target referent was left unmentioned (i.e. 3.3\% in Table 5). In the simple indefinite conditions more referents were left unmentioned in a matrix clause up to S5 (i.e. $16.7 \%$ in the $a(n)$-condition in Table 4 and $26.7 \%$ in the ein(e)-condition in Table 6$)$. 
Table 3. Type of referring expression used for the first re-mention of the referent in the thiscondition

\begin{tabular}{|l|r|r|r|r|r|}
\hline \multicolumn{6}{|c|}{ This-referents for all test items (mean and absolute values) } \\
\hline $\begin{array}{l}\text { Continuation } \\
\text { Sentence }\end{array}$ & Pronoun & Name & $\begin{array}{l}\text { Def. } \\
\text { unmod. NP }\end{array}$ & $\begin{array}{l}\text { Def. } \\
\text { modified } \\
\text { NP }\end{array}$ & Sum \\
\hline S1 & $10 \%(3)$ & $(0)$ & $40 \%(12)$ & $(0)$ & $50 \%(15)$ \\
\hline S2 & $13.3 \%(4)$ & $(0)$ & $6.7 \%(2)$ & $(0)$ & $20 \%(6)$ \\
\hline S3 & $3.3 \%(1)$ & $3.3 \%(1)$ & $6.7 \%(2)$ & $3.3 \%(1)$ & $16.7 \%(5)$ \\
\hline S4 & $3.3 \%(1)$ & $(0)$ & $(0)$ & $(0)$ & $3.3 \%(1)$ \\
\hline S5 & $(0)$ & $(0)$ & $(0)$ & $3.3 \%(1)$ & $3.3 \%(1)$ \\
\hline Sum & $30 \%(9)$ & $3.3 \%(1)$ & $53.3 \%(16)$ & $6.7 \%(2)$ & $93.3 \%(28)$ \\
\hline
\end{tabular}

Table 4. Type of referring expression used for the first re-mention of the referent in the $a(n)$ condition

\begin{tabular}{|c|r|r|r|r|r|}
\hline \multicolumn{7}{|c|}{$A(n)$-referents for all test items (mean and absolute values) } \\
\hline $\begin{array}{l}\text { Continuation } \\
\text { Sentence }\end{array}$ & Pronoun & Name & $\begin{array}{l}\text { Def. unmod. } \\
\text { NP }\end{array}$ & $\begin{array}{l}\text { Def. } \\
\text { modified } \\
\text { NP }\end{array}$ & Sum \\
\hline S1 & $10 \%(3)$ & $(0)$ & $26.7 \%(8)$ & $6.7 \%(2)$ & $43.3 \%(13)$ \\
\hline S2 & $6.7 \%(2)$ & $(0)$ & $6.7 \%(2)$ & $6.7 \%(2)$ & $20 \%(6)$ \\
\hline S3 & $3.3 \%(1)$ & $3.3 \%(1)$ & $3.3 \%(1)$ & $(0)$ & $10 \%(3)$ \\
\hline S4 & $(0)$ & $(0)$ & $(0)$ & $6.7 \%(2)$ & $6.7 \%(2)$ \\
\hline S5 & $(0)$ & $(0)$ & $(0)$ & $3.3 \%(1)$ & $3.3 \%(1)$ \\
\hline Sum & $20 \%(6)$ & $3.3 \%(1)$ & $36.7 \%(11)$ & $23.3 \%(7)$ & $83.3 \%(25)$ \\
\hline
\end{tabular}

More importantly, the data presented in Tables 3 through 6 show that the two types of indefinite noun phrases (headed by this or so'n vs. by the simple indefinite article $a(n)$ or ein(e)) seem not to impact the type of referring expression chosen to pick up their associated referents in the subsequent discourse. In other words, both attenuated and less attenuated types of referring expression were used for the referents associated with both indefinite this and indefinite so' $n$ and simple indefinites. Thus, Prediction 2 in (5) is not met, as the preferred type of referring expression used to pick up the direct object referents, independently of their morphological marking, are definite (unmodified) noun phrases.

At first glance, it seems that the findings presented in Tables 3 to 6 contradict Gernsbacher \& Shroyer's $(1989,539)$ results, which showed that participants used more pronouns to pick up the referents associated with this-referents compared to referents introduced by indefinite $a(n)$. One of the reasons for the different results in the two studies is due to the different ways in which the mean values for the first anaphoric item were calculated. In Gernsbacher \& Shroyer's (1989) study, the likelihood of pronominalization of the referents preceded by this was calculated relative to the likelihood of pronominalization of referents preceded by the simple indefinite article. In contrast, in the studies conducted in this paper, I investigated the 
type of referring expression used more frequently to pick up the this-referents independently of the pick-up preferences for the $a(n)$-referents.

Table 5. Type of referring expression used for the first re-mention of the referent in the so'ncondition

\begin{tabular}{|c|r|r|r|r|r|}
\hline \multicolumn{6}{|c|}{ So'n-referents for all test items (mean and absolute values) } \\
\hline $\begin{array}{l}\text { Continuation } \\
\text { Sentence }\end{array}$ & Pronoun & Name & \multicolumn{1}{l}{$\begin{array}{l}\text { Def. unmod. } \\
\text { NP }\end{array}$} & $\begin{array}{l}\text { Indef. } \\
\text { NP }\end{array}$ & \multicolumn{1}{l|}{ Sum } \\
\hline S1 & $20 \%(6)$ & $(0)$ & $60 \%(18)$ & $3.3 \%(1)$ & $83 \%(25)$ \\
\hline S2 & $(0)$ & $(0)$ & $(0)$ & $(0)$ & $(0)$ \\
\hline S3 & $(0)$ & $(0)$ & $6.7 \%(2)$ & $(0)$ & $6.7 \%(2)$ \\
\hline S4 & $(0)$ & $(0)$ & $(0)$ & $(0)$ & $(0)$ \\
\hline S5 & $(0)$ & $3.3 \%(1)$ & $3.3 \%(1)$ & $(0)$ & $6.7 \%(2)$ \\
\hline Sum & $20 \%(6)$ & $3.3 \%(1)$ & $70 \%(21)$ & $3.3 \%(1)$ & $96.7 \%(29)$ \\
\hline
\end{tabular}

Table 6. Type of referring expression used for the first re-mention of the referent in the ein(e)condition

\begin{tabular}{|c|r|r|r|r|r|}
\hline \multicolumn{6}{|c|}{ Ein(e)-referents for all test items (mean and absolute values) } \\
\hline $\begin{array}{l}\text { Continuation } \\
\text { Sentence }\end{array}$ & Pronoun & Name & $\begin{array}{l}\text { Def. } \\
\text { unmod. NP }\end{array}$ & $\begin{array}{l}\text { Def. } \\
\text { modified } \\
\text { NP }\end{array}$ & Sum \\
\hline S1 & $13.3 \%(4)$ & $3.3 \%(1)$ & $16.7 \%(5)$ & $13.3 \%(4)$ & $46.7 \%(14)$ \\
\hline S2 & $(0)$ & $(0)$ & $(0)$ & $(0)$ & $(0)$ \\
\hline S3 & $3.3 \%(1)$ & $(0)$ & $3.3 \%(1)$ & $6.7 \%(2)$ & $13.3 \%(4)$ \\
\hline S4 & $(0)$ & $(0)$ & $3.3 \%(1)$ & $6.7 \%(2)$ & $10 \%(3)$ \\
\hline S5 & $(0)$ & $(0)$ & $(0)$ & $3.3 \%(1)$ & $3.3 \%(1)$ \\
\hline Sum & $16.7 \%(5)$ & $3.3 \%(1)$ & $23.3 \%(7)$ & $30 \%(9)$ & $73.3 \%(22)$ \\
\hline
\end{tabular}

If we recalculate the mean values in Gernsbacher \& Shroyer's (1989) study so that the type of referring expression used for the this-referent is independent of that of its simple indefinite counterpart, then the results come close to those reported in this paper, as Table 7 shows. More concretely, the tendency observed in both studies is the same: the type of referring expression used to introduce the direct object referents (i.e. this-indefinite vs. $a(n)$-indefinite) does not influence the type of referring expression used to re-mention that referent.

\begin{tabular}{|l|l|l|}
\hline & This-indefinites & A(n)-indefinites \\
\hline Pronoun & $69 \%(214)$ & $67 \%(161)$ \\
\hline Definite NP & $31 \%(95)$ & $33 \%(81)$ \\
\hline Sum & $(309)$ & $(242)$ \\
\hline
\end{tabular}

Table 7. Mean and absolute values for the type of referring expressions used to take up the referents of indefinite this and $a(n)$ in Gernsbacher \& Shroyer's (1989) study

Despite the similar results observed, it is still interesting to ask why participants chose to refer back to both types of target referents by means of a pronoun in Gernsbacher 
\& Shroyer's study (1989), and not by means of a definite (unmodified) noun phrase, as in my investigation? What is the crucial factor that reversed the preference of anaphoric continuation in the two studies? I argue that the animacy of the introduced referents might play the crucial role in yielding different continuation patterns with respect to the anaphoric type of referring expression used. Note that the target items introduced in direct object position in Gernsbacher \& Shroyer's (1989) study were semantically inanimate (e.g. $a(n) /$ this egg, $a(n) /$ this vase, etc.) and the initial subject referents given in the same sentence were semantically human (usually proper names referring to persons). In the story-continuation experiments presented in this paper, both subject and target referents were semantically human. Different studies (Arnold $\&$ Griffin 2007) showed that the presence of multiple referents in a discourse reduces the use of less specified types of referring expressions to refer back to one of them. Even though the participants in the experiment reported here could have opted for more reduced types of referring expressions, as there was no competition between the referents in terms of gender (except for TI1 in Table (1)), they nevertheless chose more specified types of referring expressions (i.e. definite noun phrases). However, the findings of the study conducted here compared to Gernsbacher \& Shroyer's (1989) results, show that not only the mere presence of several referents is responsible for reducing the use of shorter anaphoric types of referring expressions, but their competition in terms or animacy ${ }^{5}$ as well. As the two referents mentioned in Gernsbacher \& Shroyer's study differ in animacy, shorter types of anaphoric referring expressions were preferred to pick up the direct object referents. In the study conducted in this paper, however, due to ambiguity-avoidance strategies, low pornominalization rates can be observed for both referents found in direct object position. All in all, the results of the present study confirm the Prediction in (4), but not the Prediction in (5).

\section{Conclusion}

The results of the exploratory studies presented in this paper revealed several patterns. First, referents associated with both indefinite this in English and indefinite so'n in German are likely to be mentioned more often in the following discourse. This observation underlines the preferential discourse status occupied by referents marked in this way, compared to referents introduced by means of the simple indefinite article. Second, despite their high referential continuity, referents headed by this and so'n do not show a higher rate of pronominaliztion compared to their simple indefinite counterparts. The findings of both Exp1 and Exp2 underline the necessity to dissociate between the likelihood of subsequent mention of a referent and the likelihood of pronominalization (confirmation of recent findings on language production, e.g. Kehler, Kertz, Rohde \& Elman 2008, Kaiser 2010), as they seem to be triggered by and to point in different factors. These two seemingly conflicting

\footnotetext{
${ }^{5}$ In a language like Romanian, which does not differentiate between [+human] and [-human] personal pronouns as English does, we would expect lower pronoun rates for multiple referents within one sentence, irrespectively of their animacy.
} 
effects suggest that it might be helpful to revise such definitions of accessibility, activation, topicality, or discourse prominence, which equally weight the likelihood of re-mention of a referent and the type of subsequent anaphoric expression used for this purpose.

Acknowledgments. I am grateful to Klaus von Heusinger and Elsi Kaiser for helpful advice during the development of this research. I would also like to thank three anonymous reviewers for their insightful comments and suggestions, as well as António Branco, Iris Hendrickx, Ruslan Mitkov and Sobha Anna for organizing the DAARC 2011 conference and for editing the present volume. This research was supported by the German Science Foundation by a grant to the project C2: Case and referential context, as part of the Collaborative Research Centre 732 Incremental Specification in Context at the University of Stuttgart, Germany.

\section{References}

1. Ariel, M.: Referring and Accessibility. Journal of Linguistics. 24, 65--87 (1988)

2. Arnold, J.: Reference form and discourse patterns. PhD dissertation, Stanford University. Dissertation Abstracts International. 59, 2950 (1998)

3. Arnold, J., Griffin, Z.: The effect of additional characters on choice of referring expressions: Everyone counts. Journal of Memory and Language. 56, 521--536 (2007)

4. Chiriacescu, S.: The presentative function of German so'n. In: Saramandu, N., Nevaci, M., Radu, C.I. (eds.) Lucrarile celui de-al treilea Simpozion International de Lingvistica, pp 345-356. Bucharest UP, Bucharest (2010)

5. Chiriacescu, S.: The discourse structuring potential of indefinite noun phrases. Special markers in Romanian, German and English. Ph.D. dissertation, University of Stuttgart (2011)

6. Chiriacescu, S., von Heusinger, K.: Discourse prominence and pe-marking in Romanian. The International Review of Pragmatics. 2(2), 298--332 (2010)

7. Gernsbacher, M., Shroyer, S.: The cataphoric use of the indefinite 'this' in spoken narratives. Memory and Cognition. 17, 536--540 (1989)

8. Givón, T.: Topic continuity in discourse: An introduction. In: T. Givón. (ed.) Topic Continuity in Discourse: A Quantitative Cross-Language Study, pp. 109-136. John Benjamins, Amsterdam, Philadelphia (1983)

9. Haspelmath, M.: Indefinite pronouns: Oxford Studies in Typology and Linguistic Theory. Oxford University Press, Oxford (1997)

10. Von Heusinger, K.: Specificity, referentiality and discourse prominence: German indefinite demonstratives. In: Ingo, R. (eds.) Proceedings of Sinn \& Bedeutung 15, pp. 9-30. Universaar - Saarland Unversity Press: Saarbrücken, Germany (2011)

11. Kaiser, E.: Investigating the consequences of focus on the production and comprehension of referring expressions. The International Review of Pragmatics. 2(2), 266--297 (2010)

12. Kehler, A., Kertz, L., Rohde, H., Elman, J.: Coherence and Coreference Revised. 
Journal of Semantics. 25, 1--44 (2008)

13. Lyons, C.: Semantics. Cambridge University Press: Cambridge (1977)

14. Maclaran, R.: The Semantics and Pragmatics of the English Demonstratives. PhD dissertation, Cornell University (1982)

15. Prince, E.: Toward a taxonomy of given-new information. In: Cole, P. (ed.)

Radical pragmatics, pp. 223--256. Academic Press, New York (1981)

16. Wright, S., Givón, T.: The pragmatics of indefinite reference: quantified textbased studies. Studies in Language 11, 1--33 (1987) 